\title{
Specialty Showcase Days: Can Specialist Careers Workshops Improve The Consideration Of ENT For Medical Students?
}

This article was published in the following Dove Press journal:

Advances in Medical Education and Practice

\author{
James Arwyn-Jones ${ }^{1, *}$ \\ Sanjana Bhalla $\mathbb{D}^{1}{ }^{1} *$ \\ Vikas Acharya' \\ Issa Beegun ${ }^{2}$ \\ Zaid Awad (D) \\ Neil Tolley'
}

'Otolaryngology Department, Imperial College Healthcare NHS Trust, The Bays, London W2 INY, UK; ' 2 Otolaryngology Department, Barts Health NHS Trust,

Trust Headquarters, The Royal London Hospital, London, EI 2ES, UK

*These authors contributed equally to this work
Correspondence: James Arwyn-Jones Undergraduate Education Office, Reynolds Building, Imperial College London, Charing Cross Campus, St Dunstan's Road, London W6 8RP, UK Tel +442033 I I58I I

Email james.jones12@nhs.net
Objective: We hypothesize that poor consideration of specialist surgery is due to a lack of exposure to information about careers and practice itself. Ear, Nose, and Throat (ENT) surgery is given little weight in medical school curricula, despite ENT problems being extremely common. Our objective is to assess whether a specialty showcase day was sufficient to boost informed consideration of this career.

Design: We designed a half-day course involving an interactive careers workshop exploring ENT as a specialty choice, alongside simulation stations of commonly presenting ENT problems led by ENT doctors. We used pre- and post-course evaluation sheets to explore factors that encourage and discourage students from surgical careers and perceptions of ENT. Setting: A large proportion of UK medical schools do not offer ENT placements, and of those that do, nearly half are not compulsory. This leaves students unaware of ENT as a career option and unclear about what an ENT career comprises. Our half-day course took place in the simulation suite at St Mary's Hospital, London.

Participants: Medical students were mainly in their third year of study and had aspirations towards a variety of surgical and non-surgical careers, with a minority aspiring towards ENT before the course.

Results: Our results demonstrate that all students found the session useful and had a much better understanding of ENT practice, with almost all students leaving more likely to consider a career in ENT.

Conclusion: We would like to repeat this session in different student year groups and compare their perceptions with our results. We find our results a good case for including informative careers workshops as part of medical school teaching. We pose that interactive workshops exploring specialist surgical careers are a valid way to enable students in making informed career decisions - particularly in specialties that are under-represented at medical school.

Keywords: undergraduate education, careers, specialist surgery, otorhinolaryngology, simulation

\section{Introduction}

Ear, Nose, and Throat Surgery (ENT), or otolaryngology, is a niche surgical specialty in the United Kingdom (UK). As a specialty, clinicians are surgically trained, but unlike most other surgical specialties, there is no direct medical specialty equivalent. As such, ENT doctors additionally care for patients with complex medical problems that are associated with ENT disease. All areas of ENT practice (whether general or subspecialist) include management of acute and 
chronic diseases, which are often complex and require sophisticated investigations to aid diagnosis. To our knowledge, there are no dedicated careers teaching sessions within UK medical schools that enable consideration of careers specifically in ENT for students - rather, they have to attend talks, undertake independent research or speak to mentors to gather more information regarding the specialty. Finding mentors can be difficult with little weight currently given specifically to ENT in current medical school curricula. This article will explore the exposure and current teaching of ENT within UK medical schools, and propose a dedicated careers teaching session that may improve the likelihood of medical students to consider a career in this specialty.

\section{Training In Medical School In The UK}

There are currently 33 medical schools in the UK. ${ }^{1}$ The General Medical Council (GMC) offers guidance broadly related to the desired career outcomes of graduates and how medical schools may achieve this. ${ }^{2}$ Emphasis, however, should be placed on the word "guidance". There is large variability between medical schools on how best to achieve these outcomes, including different curriculum designs. There are several approaches described by the BMA for training at medical school. These include casebased learning, problem-based learning, enquiry-based learning, clinical teaching, systems-based teaching, and inter-professional learning. ${ }^{3}$ Different institutions vary in the weight they give to each style of teaching.

\section{Exposure To Surgery At Medical School}

Generally, medical students spend four to six years at university. The variability depends on whether students enter medical school as an undergraduate or postgraduate student and the university itself (its provision of intercalated degrees, for instance). According to the GMC, "clinical placements must be appropriately structured to give each student experience across a range of specialties". 4 There is no available guidance, however, for how long each rotation should be, resulting in discrepancies between medical schools. Undergraduates have felt low satisfaction from surgical rotations during medical school and have expressed that they feel more prepared for their foundation jobs in surgery if they have had more time during their undergraduate years in a surgical specialty. ${ }^{5}$ Currently, it is felt that there is a poor representation of ENT in the medical school curriculum. A recent study of 26 medical schools showed that there were compulsory ENT placements for just $53 \%$ of the students and 10 of the 26 medical schools included in the study did not offer an ENT attachment at all. ${ }^{6}$ The average duration of ENT attachment in medical school varies from 7.5 to 13.4 days. ${ }^{6,7}$ The short length of ENT attachments, or indeed the absence of them, maybe inadequate; particularly as more than 1 in 10 presentations to General Practice involve ENT pathology. ${ }^{8}$ A review of the undergraduate curricula revealed that most final-year students do not feel adequately prepared to practice ENT due to (short) duration of clinical rotations and the opportunity (or lack, thereof) they have had for practical learning. ${ }^{9}$ It is not surprising, therefore, that many students do not consider ENT as a career when they do not have the chance to fully experience or partake in the various aspects of this unique specialty.

\section{Training Pathway For ENT In The UK}

To become an ENT specialist in the UK, graduates must initially complete two years of foundation training. After this, they must complete two years of core surgical training and then apply for an otolaryngology ST3 higher surgical training number, which if obtained, enters them into six years of specialty training. Upon completing six years of higher surgical training, also known as ST3-ST8, they may apply for Certification of Completion of Training (CCT) to become an ENT consultant and enter onto the GMC specialist register. Since 2018, a new ENT pilot scheme is in place so that during the second year of foundation training, trainees can apply for an ENT ST1 number, and enter directly onto a run-through specialty training programme to ST8, such that there is no re-application at ST3 level. There are very few places for this pilot scheme, but it enables doctors to be trained from ST1-ST8 with no further application processes. In 2018, there were 1870 applications for core surgical training and 636 posts making the competition ratio 2.94. There were 132 applications for otolaryngology as ST3 for 56 posts, making the competition ratio $2.36 .{ }^{10}$ For general surgery and vascular surgery ST3, there were 396 applications and 257 posts making the competition 1.54. Therefore, we can see that ENT is a popular specialty choice and remains competitive. As competition increases, it is essential that trainees are prepared, and starting preparation in medical school could be beneficial for career planning. One is only able to achieve this if they are aware of the specialty, have some insight into day-today practice, and have some clinical exposure, increasing awareness of specialty as a potential long-term career. 


\section{Influences On Career Choice}

Reasons for choosing a career in surgery at undergraduate level include experience of surgical skills workshops, conferences, career talks, as well as membership to various surgical societies. ${ }^{11}$ At postgraduate level, it has been found that rotations in general surgery shape preferences towards general surgery as a career. ${ }^{12}$ However, if junior doctors wait until foundation years to choose a specialty, it may be considered too late when accounting for the competition ratios for surgical specialties, as early preparation enables easier transitions into specialty training posts. Therefore, we propose that focused careers sessions at undergraduate level may improve the likelihood of students to consider a career in surgery, and in this case, specifically ENT Surgery.

\section{Materials And Methods}

A small prospective cohort observational study was undertaken in the simulation laboratory at St Mary's Hospital, Paddington, UK.

No patients were involved in this study and therefore patient consent was not required. Ethical approval was also not formally sought for this project, but departmental approval was granted for the project to be undertaken. A half-day teaching course was designed and executed as follows:

- A focused interactive careers talk and workshop related to considering ENT as a future career choice. This included various aspects of a career in ENT, including day-to-day practice and commitments, training, worklife balance, job security, and financial security.

- 4 ENT simulation stations (small groups of 2-3 students) led by ENT Senior House Officers (SHOs), each of which included a short presentation of the topic and hands-on practical experience of relevant skills:

1. Ears - short presentation covering common otology pathologies and practical experience of otomicroscopy, microsuction, and grommet insertion.

2. Nose - short presentation covering common rhinology pathologies and practical experience of cautery and nasal packing.

3. Throat - short presentation covering common laryngology pathologies and those of the oropharynx, and practical experience of peritonsillar abscess drainage and flexible nasendoscopy.

4. Front of neck airway - short presentation about tracheostomies and their care, and practical experience of tracheostomy tube change.
The above course was delivered to 11 medical students (10 third-year medical students and 1 final-year medical student) at Imperial College London. Pre and post session evaluation forms were used to assess knowledge of career planning/pathway as well as confidence in dealing with the common ENT emergencies. The evaluation forms included qualitative and quantitative data, and example forms are included in the Appendices of this article.

\section{Results \\ Pre-Course Feedback}

The pre-course feedback revealed that students in attendance at the course had a broad range of career aspirations. The majority of students $(n=6)$ were aspiring surgeons, with the career aspirations of others ranging to include:

- Paediatrics $(\mathrm{n}=2)$

- Academia/Research $(\mathrm{n}=2)$

- Medicine $(\mathrm{n}=1)$

- General Practice $(\mathrm{n}=1)$

- Emergency Medicine $(\mathrm{n}=1)$

- Intensive Care Medicine/Anaesthetics ( $\mathrm{n}=1)$

- Public Health and Paediatrics $(n=1)$

- Note that some students selected more than one career aspiration

Ten students were considering a career in surgery, and 5 were considering a career in ENT. Most $(n=10)$ students expressed that a presentation related to ENT careers would be helpful in the curriculum.

When asked about encouraging and discouraging factors when thinking about a surgical career, the following results were seen (Figures 1 and 2).

The students were also asked to rate their knowledge of aspects involved in a career in ENT. The results are shown in Table 1.

\section{Post-Course Feedback}

All of the students thought that the course was pitched at the right level and that there was about the right amount of content covered. Overall, they thought the course was stimulating, enjoyable, informative, practical, worthwhile, interesting, relevant, and clear. They were also asked questions about their perceptions of ENT, as shown in the following diagram (Figure 3) 


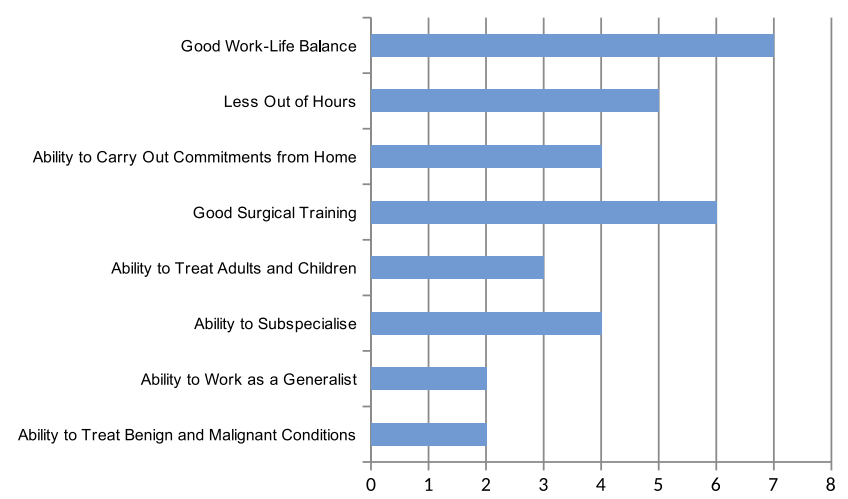

Figure I Factors encouraging a surgical career $(0=$ no encouragement of surgical career, 10 = extremely encouraging for a surgical career).

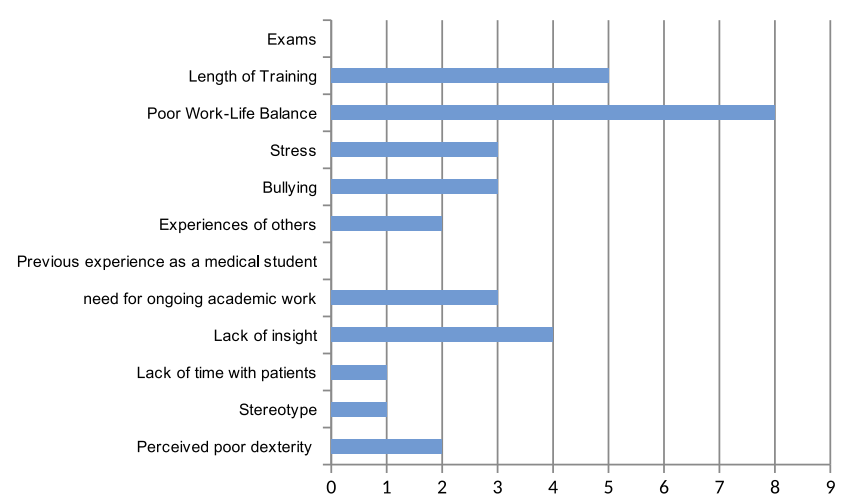

Figure 2 Factors discouraging a surgical career $(0=$ no discouragement from surgical career, $10=$ extremely discouraging of a surgical career).

After the course, students were also asked to repeat the ratings of their knowledge of aspects involved in a career in ENT (see Table 1). The results are shown in Table 2.

\section{Discussion}

\section{What Results Show}

The aim of our careers session was to provide information and experience around ENT careers and practice to students, to enable them to make informed decisions about choosing a career in surgery and specifically, ENT.

Of the 11 students in attendance at this course, the precourse feedback forms show that 10 were broadly considering a career in surgery and 5 were considering a career in ENT. When asked about current career aspirations; however, 5 of the 11 students were aspiring for careers other than surgery (and therefore ENT). The students in this latter category had current aspirations towards careers in a variety of specialties, both medical and surgical, and unrelated to ENT. The proportion of students here already considering ENT careers introduces inherent bias into our results and may reduce the effective number of students our intervention targets. However, their inclusion is still useful to validate the use of specialty showcase days, even if the change across their pre- to post-course evaluations is smaller than others. We would also argue that in the third year of study, students are considering a wide range of specialties, with many doctors not reaching a conclusion until after medical school. As such, the provision of this course to those considering ENT careers is not invalid or wasted, as these students may be disadvantaged most by under-representation of ENT in the curriculum.

It appears that factors discouraging some students from a career in surgery included perceptions of poor work-life balance, length of training, and lack of insight into what a surgical career may entail. Aspects of surgery that attracted some students to surgical careers included good work-life balance in certain specialties, good training opportunities, and less out of hours work. It is interesting to note how prominent student perceptions of work-life balance are in encouraging or discouraging surgical careers. When asked, students felt that certain surgical specialties, including specialist areas like ENT, plastic surgery, and neurosurgery, were very competitive and required sacrifice of personal time to ensure career progression. After the short course, these

Table I Self-Rated Pre-Course Knowledge Of Aspects Involved In An ENT Career

\begin{tabular}{|l|l|l|l|l|}
\hline Rate Your Knowledge Of The Following Things Related To ENT & Complete Awareness & Rough Idea & Minimal Awareness & No Idea \\
\hline Qualifications/Exams & I & 3 & 0 & 7 \\
Training Pathway/Career in ENT & $\mathrm{I}$ & 3 & $\mathrm{I}$ & 6 \\
On Call/Out of Hours Work in ENT & $\mathrm{I}$ & 2 & $\mathrm{I}$ & 7 \\
Subspecialties/Special Interests in ENT & $\mathrm{I}$ & 2 & 2 & 6 \\
Main Setting for ENT & $\mathrm{I}$ & 5 & $\mathrm{I}$ & 4 \\
MDT Members in ENT & $\mathrm{I}$ & 2 & 2 & 6 \\
Knowledge of Common Acute ENT Pathologies & 0 & 3 & 3 & 5 \\
Confidence in Treating Common ENT Pathologies Alone & 2 & 0 & 1 & 8 \\
\hline
\end{tabular}




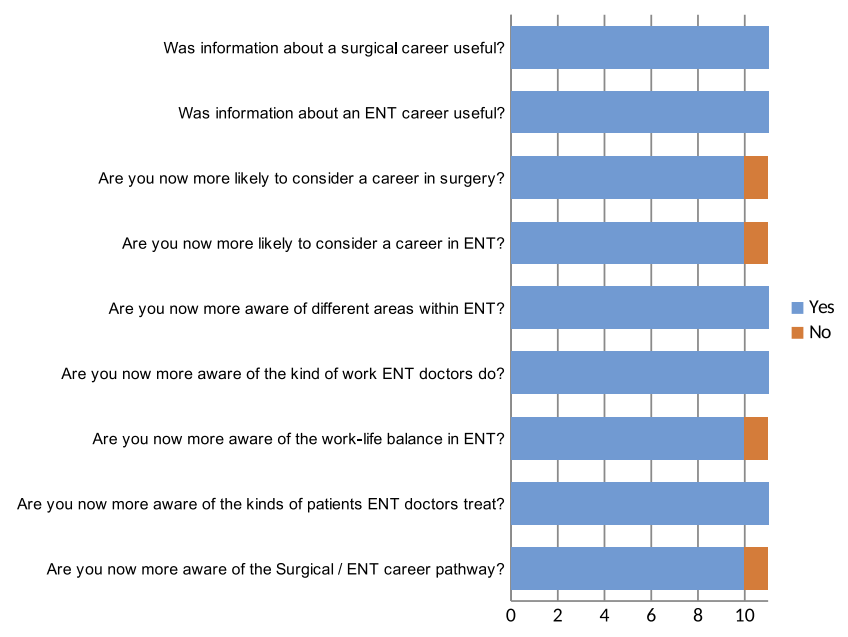

Figure 3 Post-course perceptions of ENT ( $\mathrm{x}$-axis = number of students).

perceptions began to change (seen in Figure 3) as the interactive careers session answered questions about lifestyle and dispelled common myths about competition and the day-today life of a specialist surgeon.

After the session, all students felt that the provision of information about surgical and ENT careers was useful, all felt more aware of the different areas of practice comprising ENT, the different patients managed, and what type of work ENT doctors have the opportunities to do during their training and future careers.

Ten out of 11 students felt more aware of the career pathway in ENT and the work-life balance in the specialty. The same number of students felt more likely to consider a career in surgery and ENT in particular after the course. This highlights the value of the provision of information and practical experience in surgical careers such as ENT. The format we have used gives students the opportunity to make decisions about future career aspirations and considerations based on actual experience and more detailed information about the specialty.
Overall, there has been marked improvement in student perceptions of ENT across all of our parameters of measurement. From this we gather that a specialist surgery teaching course (in ENT in our case) for medical students is a valuable way of adequately exposing students to smaller specialties, enabling them to make informed decisions about future career decisions.

\section{Proposed Interventions Into Medical School Curricula}

As mentioned previously, not all medical schools in the UK offer a compulsory ENT placement. ${ }^{6}$ We suggest that all medical schools should include a compulsory ENT placement. ENT presentations are common in front-line health-care settings such as General Practice (GP) and Emergency Medicine. ${ }^{13}$ Foundation year rotations commonly include GP and/or Emergency Medicine, and many will encounter ENTrelated complaints on various other inpatient wards. As such, we propose that a compulsory rotation in medical school would be beneficial to ensure all junior doctors have an awareness of and can manage common ENT presentations. This is important not only for front-line management of common conditions but also, and importantly, for a working knowledge of in what circumstances a specialty referral is necessary. Furthermore, placements within the specialty have been shown to influence career choice of medical students, ${ }^{8,12}$ and we argue that students should have the opportunity to explore ENT in order to make informed decisions about their future careers.

\section{Influences On Career Choice And How To Improve}

It has been shown that there are many factors that influence the choice of undergraduate medical students to choose surgery. Even before medical school, it has been shown that work experience placements that include

Table 2 Self-Rated Post-Course Knowledge Of Aspects Involved In An ENT Career

Rate Your Knowledge Of The Following Things Related To ENT

\begin{tabular}{|l|l|l|l|l|}
\hline & Complete Awareness & Rough Idea & Minimal Awareness & No Idea \\
\hline Qualifications/Exams & 4 & 4 & $\mathrm{I}$ & $\mathrm{I}$ \\
Training Pathway/Career in ENT & 4 & 3 & $\mathrm{I}$ & 0 \\
On Call/Out of Hours Work in ENT & 4 & 4 & $\mathrm{I}$ & 0 \\
Subspecialties/Special Interests in ENT & 5 & 4 & $\mathrm{I}$ & 0 \\
Main Setting for ENT & 5 & 3 & 2 & 0 \\
MDT Members in ENT & 4 & 3 & 2 & $\mathrm{I}$ \\
Knowledge of Common Acute ENT Pathologies & 6 & 3 & $\mathrm{I}$ & $\mathrm{I}$ \\
Confidence in Treating Common ENT Pathologies Alone & 4 & 4 & $\mathrm{I}$ \\
\hline
\end{tabular}


surgical placements for school students can influence future career choice for surgery. ${ }^{14}$ Previous work has suggested that factors making surgery a popular choice amongst medical students include an interest in specific specialties and perceptions of work-life balance - the mechanisms of exposure to these influences and perceptions are generally via mentors and surgical societies. ${ }^{14}$ From our study, we have seen that the main influences among our students include work-life balance, training opportunities, and out of hours work.

This is in keeping with previous work, as work-life balance was the main influencing factor. The remaining influence is somewhat dependent on exposure to the specialty, either via surgical societies, or direct contact with the specialty to enable mentoring, role modelling, and experience of day-to-day practice. This adds to the argument that rotations in smaller specialties like ENT are important to enable informed career planning for medical students. Colleagues within the medical school should be educated regarding the importance of medical education within each specialty, as this encourages learning and understanding of available career pathways.

As exposure to ENT is very limited, everything possible should be done to maximise the potential from a short rotation. During ENT placements, there has been a higher student satisfaction when students are able to see patients alone therefore this could be incorporated into ENT rotations, for example, in dedicated teaching clinics with fewer patients and more time for learner-educator interaction. ${ }^{15}$ Training could also be improved by using workbooks and teaching sessions to develop deeper understanding of the material rather than through shadowing alone. ${ }^{16}$ It has been suggested that "nearpeer learning" is a beneficial method in teaching anatomy of the head and neck to undergraduate students. ${ }^{17}$ This could be incorporated to enhance learning of ENT. The established definition of near-peer learning is understood to be education facilitated by colleagues in close proximity and seniority to the learner. For medical students, this tends to result in the view of near-peer learning as student-to-student education. In ENT this may be difficult as much of the necessary knowledge base is specialist, so for this reason it may be prudent to actively involve junior members of the team (foundation doctors and core trainees) in the provision of ENT teaching, as we have in our session.

The GMC's "Tomorrows doctors" ${ }^{2}$ highlights the importance of medical education within training. For applications to core surgical training as well as higher surgical training, there are certain criteria regarding teaching experience, which are used in the selection process. For students rotating throughout the ENT specialty, all ENT trainees should be encouraged to actively teach the students, whether this be ward rounds, bedside teaching, lectures, or hands-on teaching of practical skills. From our assessments, students emphasise that positive experience within the rotation influences their decision for future careers. This would not only improve the learning experience for the students but also make them feel actively engaged and participants in the clinical exposure as their theory will be applied into clinical practice. ${ }^{18}$ Our teaching course is an example of an option that works in improving perceptions regarding ENT careers and involves junior members of the ENT team providing a solid foundation in relevant ENT knowledge to students. If the provision of an ENT rotation is not possible during medical school, we would suggest that a half-day course like ours is provided to enable exposure to smaller specialties and enhance informed careers decision-making.

\section{Limitations}

This study has highlighted the fact that medical students have minimal exposure to ENT during medical school training, and a dedicated session that we provided has left them better informed about a career in ENT.

The two main limitations of our study are the small sample size and the inherent bias within the sample group. The implication of the small sample size is to reduce the validity of our result and makes it incorrect to attempt to perform statistical testing on the results. However, we believe the results are clear without statistical tests and do show clear benefit of the specialty showcase day and certainly validate our methods. This is useful, as our methodology will now be repeated to gain a more robust sample.

The small sample size may be related to the fact that our course was free of charge. This resulted in a large number of unforeseen non-attendances on the day, given no financial incentive to attend. As such, if taken forward, for future courses for undergraduates it may be prudent to charge a deposit, whereby attendance guarantees a refund, or incorporate this practical course as a compulsory part of the current ENT undergraduate rotation.

Bias is clearly introduced into our study, as the students who were chosen for the session were those who expressed an interest in participating. Many of the students expressed a surgical interest and indeed an interest in ENT prior to participating in the specialty showcase day. As mentioned earlier, however, specialty considerations in year 3 medical students often change, and their prior perceptions of ENT do not 
invalidate the results or the methodology used. We would suggest that these students might even be disadvantaged most from lacking ENT provision in a medical school curriculum. The bias in our study may be reduced in the future with a broader variety of students included, and this may improve with the collection of more results in future sessions. Selfselecting attendees may always bring an element of inherent bias, however, and so this should be expected unless specialty showcase days are made compulsory.

We decided to provide this session to medical students at Imperial College London, the majority of whom were thirdyear students. ENT rotations at Imperial College London take place in the final year of training, and perhaps this session would be more useful during an ENT rotation as it teaches skills to allow students to become more involved during their placement. We would also like to provide sessions to other year groups to compare their perceptions with our results.

We also believe that specialty showcase days may be useful for junior doctors, many of who decide on a surgical career during their foundation years. Therefore, this same session could be provided to foundation year doctors to showcase ENT as an option. This could also be widened to other surgical specialties as we have only focused on ENT.

\section{Conclusion}

A dedicated and interactive simulated careers teaching session can help improve the likelihood for medical students to consider a career in ENT Surgery. Having formal sessions allows them to gain insight, prepare for forward planning, and encourages rotations in this specialty. This should be implemented every year into the medical school curriculum for ENT as well as other specialties to enable medical students to be better informed and seek help from others early on, particularly in medical schools that do not provide placements in smaller specialties. As competition ratios increase for ENT, it is crucial that one prepares early to avoid disappointment in applying for higher surgical training or run-through training following foundation and/or core training. We believe that including practical experience of common presentations to a specialty in a careers course will also enhance the ability of students to make informed decisions and should be made available where practically possible. It increases awareness of what is expected of doctors working in the specialty, which is important when considering any medical or surgical specialty.

\section{Disclosure}

The authors report no conflicts of interest in this work.

\section{References}

1. Maxwell S, Walley T. Teaching safe and effective prescribing in UK medical schools: a core curriculum for tomorrow's doctors. $\mathrm{Br}$ $J$ Clin Pharmacol. 2003;55(6):496-503. doi: 10.1046/j.13652125.2003.01878.x

2. Christopher DF, Harte K, George CF. The implementation of Tomorrow's Doctors. Med Educ. 2002;36(3):282-288. doi:10.1046/ j.1365-2923.2002.01152.x

3. Feeley AM, Biggerstaff DL. Exam success at undergraduate and graduate-entry medical schools: is learning style or learning approach more important? A critical review exploring links between academic success, learning styles, and learning approaches among school-leaver entry ("traditional") and graduate-entry ("nontraditional") medical students. Teach Learn Med. 2015;27(3):237-244. doi:10.1080/10401334.2015.1046734

4. Brennan N, Corrigan O, Allard J, et al. The transition from medical student to junior doctor: today's experiences of Tomorrow's Doctors. Med Educ. 2010;44(5):449-458. doi:10.1111/j.1365-2923.2009.03604.x

5. Drake TM, Malik TA, O'Connor T, Daoub A, Chebbout R, Lee MJ. Has the bachelor of surgery left medical school? Int J Surg. 2015;23: S97. doi:10.1016/j.ijsu.2015.07.451

6. Khan MM, Saeed SR. Provision of undergraduate otorhinolaryngology teaching within general medical council approved UK medical schools: what is current practice? J Laryngol Otol. 2012;126(4):340344. doi: $10.1017 / \mathrm{S} 0022215111003379$

7. Sharma A, Machen K, Clarke B, Howard D. Is undergraduate otorhinolaryngology teaching relevant to junior doctors working in accident and emergency departments? J Laryngol Otol. 2006;120 (11):949-951. doi:10.1017/S0022215106002246

8. Griffiths E. Incidence of ENT problems in general practice. $J R$ Soc Med. 1979;72(10):740-742. doi:10.1177/014107687907201008

9. Ferguson GR, Bacila IA, Swamy M. Does current provision of undergraduate education prepare UK medical students in ENT? A systematic literature review. BMJ Open. 2016;6(4):e010054. doi:10.1136/bmjopen-2015-010054

10. Wilmot VV, Davis JP, Carrie S. National ENT workforce planning in the United Kingdom; An increasing cause for concern? Clin Otolaryngol. 2018;44(3):213-218. doi:10.1111/coa.13241

11. Ologunde R, Rufai SR, Lee AH. Inspiring Tomorrow's surgeons: the benefits of student surgical society membership $\square$ ? J Surg Educ. 2015;72(1):104-107. doi:10.1016/j.jsurg.2014.06.004

12. Al-Heeti KN, Nassar AK, DeCorby K, Winch J, Reid S. The effect of general surgery clerkship rotation on the attitude of medical students towards general surgery as a future career. J Surg Educ. 2012;69 (4):544-549. doi:10.1016/j.jsurg.2012.04.005

13. Mahalingam S, Seymour N, Pepper C, Tostevin P, Oakeshott P. Reducing inappropriate referrals to secondary care: our experiences with the ENT emergency clinic. Qual Prim Care. 2014;22:251-255.

14. Sutton PA, Mason J, Vimalachandran D, McNally S. Attitudes, motivators, and barriers to a career in surgery: a national study of UK undergraduate medical students. $J$ Surg Educ. 2014;71(5):662-667. doi:10.1016/j.jsurg.2014.03.005

15. Hajioff D, Birchall M. Medical students in ENT outpatient clinics: appointment times, patient satisfaction and student satisfaction. Med Educ. 1999;33(9):669-673. doi:10.1046/j.1365-2923.1999.00422.x

16. Carr ER, Jones M, Pankhania M, Ali K, Pau H. An audit of student satisfaction with under graduate ENT surgery teaching. Ann R Coll Surg Engl. 2013;95(4):1-3. doi:10.1308/147363513X13500508920211

17. Morris S, Osborne MS, Bowyer D. Head and neck anatomy: effect of focussed near-peer teaching on anatomical confidence in undergraduate medical students. $J$ Surg Educ. 2018;75(6):1486-1490. doi:10.1016/j.jsurg.2018.04.013

18. Acharya V, Reyahi A, Amis SM, Mansour S. Do "trainee-centered ward rounds" help overcome barriers to learning and improve the learning satisfaction of junior doctors in the workplace? Adv Med Educ Pract. 2015;6:583. doi:10.2147/AMEP.S90254 


\section{Publish your work in this journal}

Advances in Medical Education and Practice is an international, peerreviewed, open access journal that aims to present and publish research on Medical Education covering medical, dental, nursing and allied health care professional education. The journal covers undergraduate education, postgraduate training and continuing medical education including emerging trends and innovative models linking education, research, and health care services. The manuscript management system is completely online and includes a very quick and fair peer-review system. Visit http://www.dovepress.com/testimonials.php to read real quotes from published authors.

Submit your manuscript here: http://www.dovepress.com/advances-in-medical-education-and-practice-journal 